\section{$\mathrm{Y}-12$}

OAK RIDGE

$Y-12$

PLANT

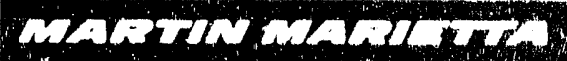

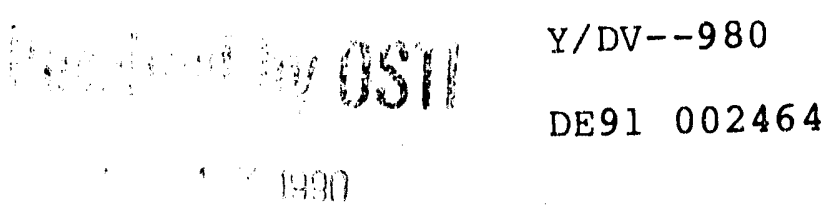

CARBON REDUCTION IN URANIUM ALLOYS UTILIZING HAFNIUM ADDITIONS

\author{
G. Mackiewicz-Ludtka \\ W. C. Pullen \\ C. A. Henderson \\ Materials Engineering Department \\ Development Division \\ W. Chu \\ M. W. Wendel \\ Computer and Telecommunications Division \\ Oak Ridge Gascous Diffusion Plant
}

Date of Issue: August 14, 1990

Prepared by the

Oak Ridge Y-12 Plant

operated by

MARTIN MARIETTA ENERGY SYSTEMS, INC.

for the

U.S. Department of Energy

under contract DE-AC05-84OR21400
OPERATEO BY

MARTIN MARIETTA ENIROY SYSIEMS N

FOR THE UNITEG STATSS

DEPARTMENT OF FNERTiY 
This report has been reproduced directly from the best available copy:

Available to DOE and DOE contractors from the Office of Scientific and Technical Information, P.O. Box 62, Oak Ridge, TN 37831; prices available from (615) 576-8401, FTS 626-8401.

Available to the public from the National Technical Information Service, U.S. Department of Commerce, 5285 Port Royal Rd., Springfield, VA 22161

\section{Price: Printed Copy}

Microfiche A01

\section{DISCLAIMER}

This report was prepared as an account of work sponsored by an agency of the United States Government. Neither the United States Government nor any agency thereof, nor any of their employees, makes any warranty, express or implied, or assumes any legat liability or responsibility for the accuracy, completeness, or usefulness of any information, apparatus, product, or process disclosed, or represents thât its use would not intringe privately owned rights. Reference herein to any spectic commercial product, process, or service by trade name, trademark, manu. facturer, or otherwise, does not necessarily constitute or imply its endorsement, recommendation, or favoring by the United States Government or any agency theseot. The views and opinions of authors expressed herein do not necessarily state or reflect those of the United States Government or any agency thereof. 


\title{
CARBON REDUCTION IN URANIUM ALLOYS UTILIZING HAFNIUM ADDITIONS
}

\author{
G. Mackiewicz-Ludtka, W. C. Pullen, C. A. Henderson, W. Chu and M. W. Wendel
}

\section{$\underline{\text { SUMMARY }}$}

Vacuum-induction casting experiments have demonstrated that hafnium (Hf) additions to unalloyed uranium (U) reduce carbon $(\mathrm{C})$ levels by approximately $80 \%$ in up to $6.0 \mathrm{in}$. in depth in $5 \times 7 \times 15$ in. (width $\times$ depth $\times$ thickness) book mold castings. Analytic modeling of the solidification process was initiated to compare the calculated/predicted thermal profile to the actual experimentally measured temperatures. Temperature profile predictions matched the experimental values at the top of the casting and accurately determined that the predominant heat loss is out the bottom of the book mold assembly. However, the model overpredicts the temperature half way down the length of the casing. The boundary heat transfer coefficient at the bottom of the casting needs to be more accurately simulated.

\section{INTRODUCTION}

With increasing environmental concerns regarding the handling and storage of uranium waste, recycling previously used material is becoming exceedingly more important. Carbon is one of the primary trace impurities that builds up in uranium with repeated use. The goal of this study is to reduce carbon in recycled uranium during the casting process to carbon levels associated with virgin uranium derbies.

\section{PRIOR WORK}

Previously, others ${ }^{2,3}$ have evaluated the chemical reactions typically associated with carbide formation in liquid uranium alloys. These chemical reactions are due to the following three sources: 1) oxygen $\left(\mathrm{O}_{2}\right)$ and water vapor $\left(\mathrm{H}_{2} \mathrm{O}\right)$ leakage into the vacuum casting furnace from the atmosphere; 2$)$ yttria coating $\left(\mathrm{Y}_{2} \mathrm{O}_{3}\right)$ and graphite (C) mold interactions; and 3$)$ the liquid $\mathrm{U}$-vacuum interface. The chemical reactions associated with these sources can be summarized as follows:

$$
\begin{aligned}
& \mathrm{O}_{2}(\mathrm{~g})+2 \mathrm{C}(\mathrm{s}) \rightarrow 2 \mathrm{CO}(\mathrm{g}) \\
& \mathrm{H}_{2} \mathrm{O}(\mathrm{g})+\mathrm{C}(\mathrm{s}) \rightarrow \mathrm{CO}(\mathrm{g})+\mathrm{H}_{2}(\mathrm{~g}) \\
& \mathrm{Y}_{2} \mathrm{O}_{3}(\mathrm{~s})+7 \mathrm{C}(\mathrm{s}) \rightarrow 2 \mathrm{YC}_{2}(\mathrm{~s})+3 \mathrm{CO}(\mathrm{g}) \\
& 2 \mathrm{CO}(\mathrm{g})+3 \mathrm{U}(\mathrm{l}) \rightarrow 2 \mathrm{UC}(\mathrm{s})+\mathrm{UO}_{2}(\mathrm{~s}) \\
& \mathrm{CO}(\mathrm{g})+2 \mathrm{U}(\mathrm{s}) \rightarrow \mathrm{UC}(\mathrm{s})+\mathrm{UO}(\mathrm{s})
\end{aligned}
$$


Reiner and Holcomb ${ }^{3}$ evaluated the reaction kinetics between liquid uranium and uranium-niobium (U-Nb) alloys with carbon monoxide (as functions of alloy composition, exposure time, exposure temperature, $\mathrm{CO}$ pressure, and specific surface area of the liquid. vacuum interface). These authors experimentally determined that the $\mathrm{CO}$ reaction is at least ten times as important with respect to carbon contamination of uranium alloys as the yttria coating interaction with the graphite mold. However, no published work has been located which evaluates the formation of carbides as a method for reducing or eliminating carbon in uranium castings.

The work described in this report is aimed at utilizing additions of elements which have a high propensity to form low-density, energetically favorable, carbides. Hafnium is one such elemental addition and is considered in this report.

\section{PRESENTATION OF EXPERIMENTAL WORK}

\section{Approach and Experimenıal Procedures}

Since Hf combines readily with $\mathrm{C}$ to form HfC (See Table 1) and HfC is significantly less dense than liquid uranium (the density of liquid uranium $\left(\rho_{u}\right)$ is $17.7 \mathrm{~g} / \mathrm{cm}^{3}$, and that of HrC $(\rho \mathrm{HFC})$ is $\left.12.6 \mathrm{~g} / \mathrm{cm}^{3}\right)$, the initial approach has been to add trace amounts of $\mathrm{Hf}$ to $\mathrm{U}$ to "float out" the carbon in $U$ during the casting process.

Several U-Hf castings have been prepared from approximately $18 \mathrm{~kg}$ of $\mathrm{U}$ and a trace amount of Hf. The $\mathrm{Hf}$ was added as a prealloyed $\mathrm{U}$-Hf button and co-melted with the $\mathrm{U}$ containing 200 to $225 \mathrm{ppm}$ carbon in a yttria-coated graphite crucible. Platnium/platnium-10\% Rhodium thermocouples were used to determine the temperature of the metal in the crucible and along the length of the book mold. Of the three book mold thermocouples, one was located 1.0 in. from the top of the casting $\left(\mathrm{TC}_{\mathrm{TOP}}\right)$, one was placed at half height $\left(\mathrm{TC}_{\mathrm{MDL}}\right)$, and the third was 1.0 in. from the bottom $\left(\mathrm{TC}_{\mathrm{BTM}}\right)$ of the casting. The metal was heated to $1430^{\circ} \mathrm{C}$, held for 30 min. and then bottom poured into a yttria-coated graphite mold. These billets were cast as both 1.0 and $2.0 \mathrm{in.} \mathrm{thick} \mathrm{and} \mathrm{were} 5 \mathrm{in}$. wide by $7 \mathrm{in.}$ long.

Chemical analyses were taken at nine different heights along the length of the castings. Figure 1 indicates these locations. Hf levels were determined utilizing the Inductively Coupled Plasma (ICP) method and $\mathrm{C}$ levels were determined via the Leco Carion Analyzer. Metallographic samples also were taken at locations adjacent to these chemical samples to evaluate any microstructural vari. 'ions present. In additicn, a preliminary analytic model was set up to simulate the temperature profile present throughout the book mold casting so that any correspondence between carbon reductions and thermal profiles could be evaluated.

Evaluations of the standard free energies of formation of carbides that are possible in the U.C-Hf system indicates that although HfC is energetically the most favorable carbide to form at $1135^{\circ} \mathrm{C}$ (the approximate melting temperature of $\mathrm{U}$ ), at approximately $1500^{\circ} \mathrm{C}$ the $\mathrm{U}_{2} \mathrm{C}_{3}$ carbide is slightiy more energetically favorable ( 1 able 2 ). Hence, there appears to be a limited 


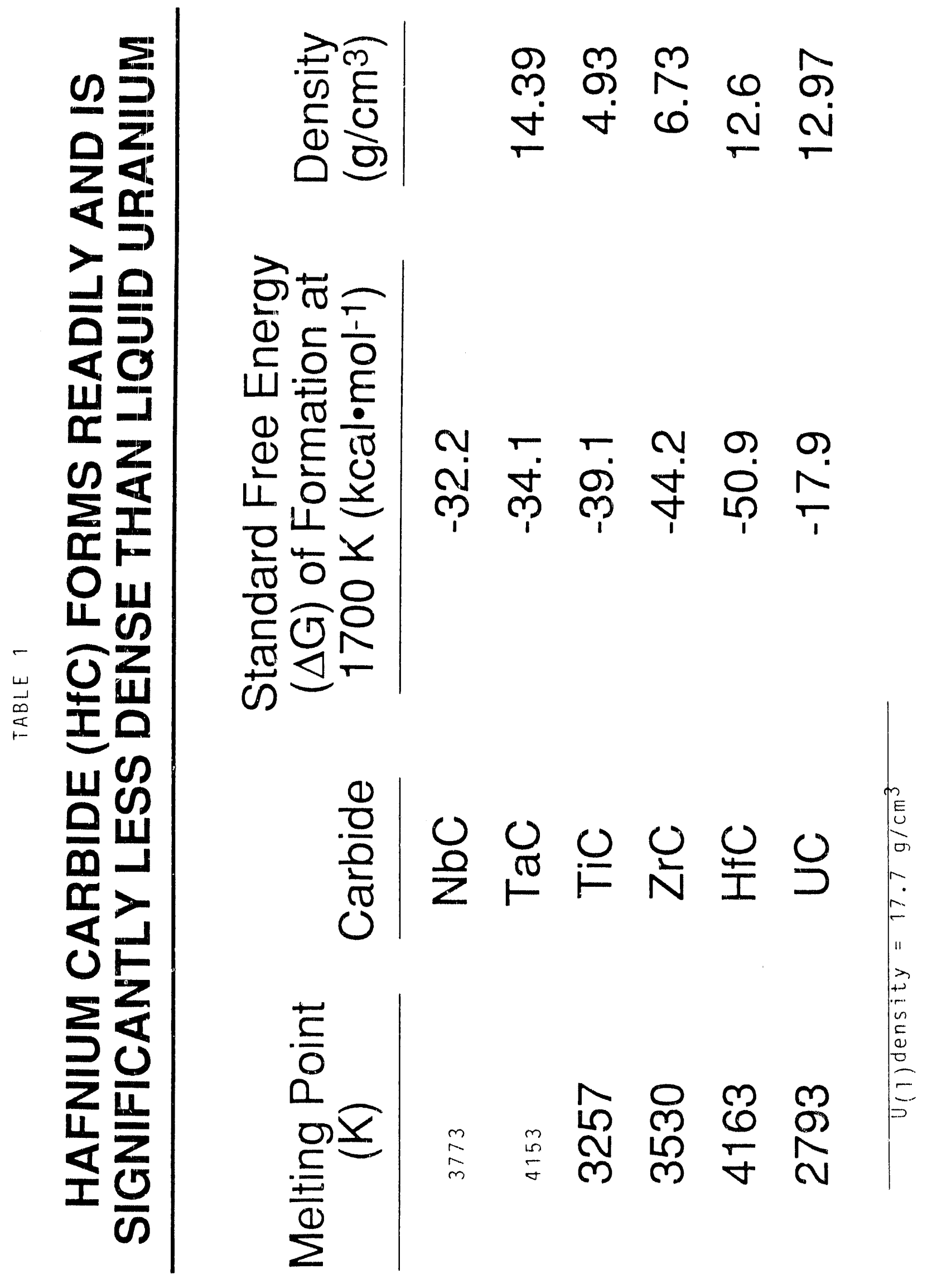




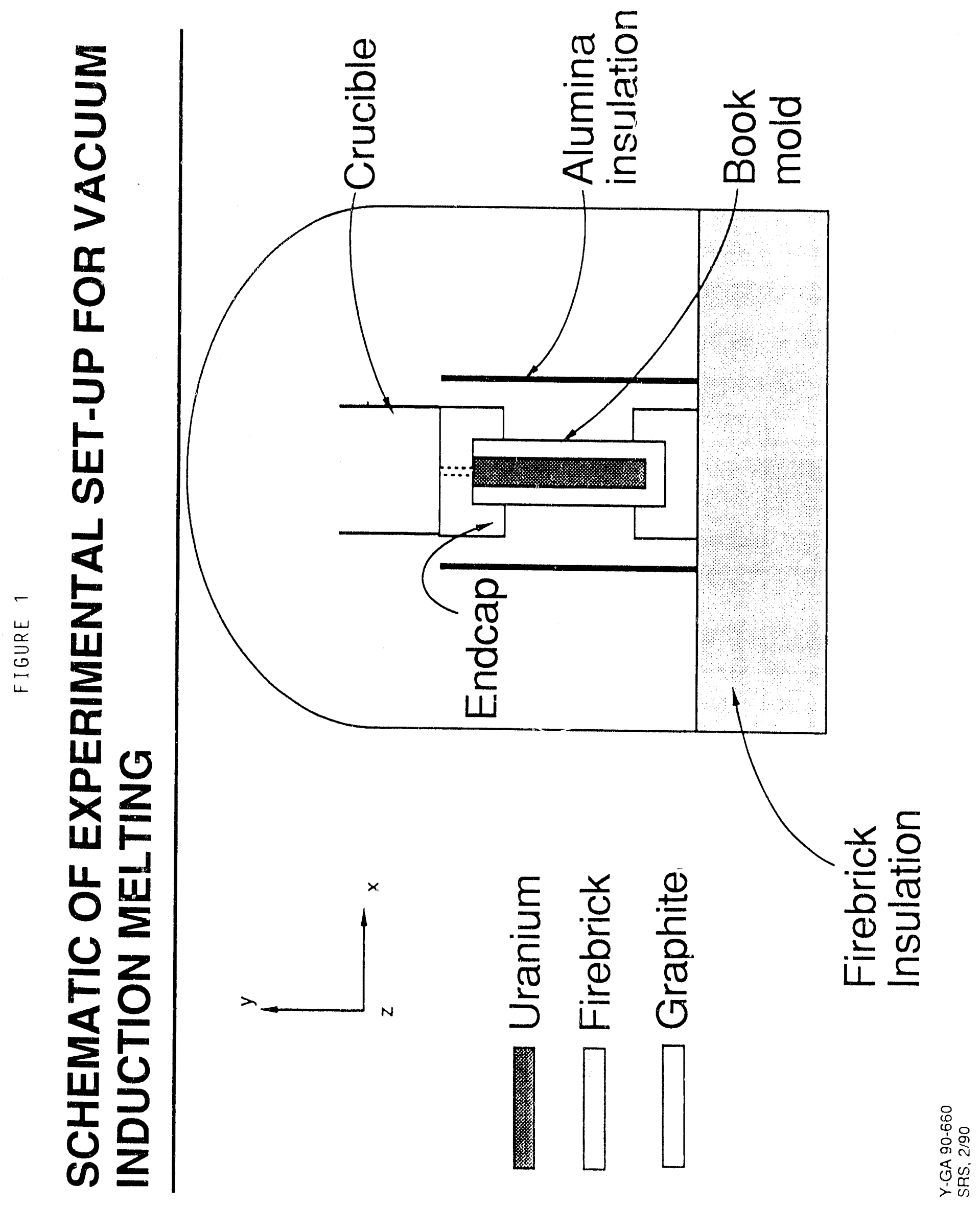




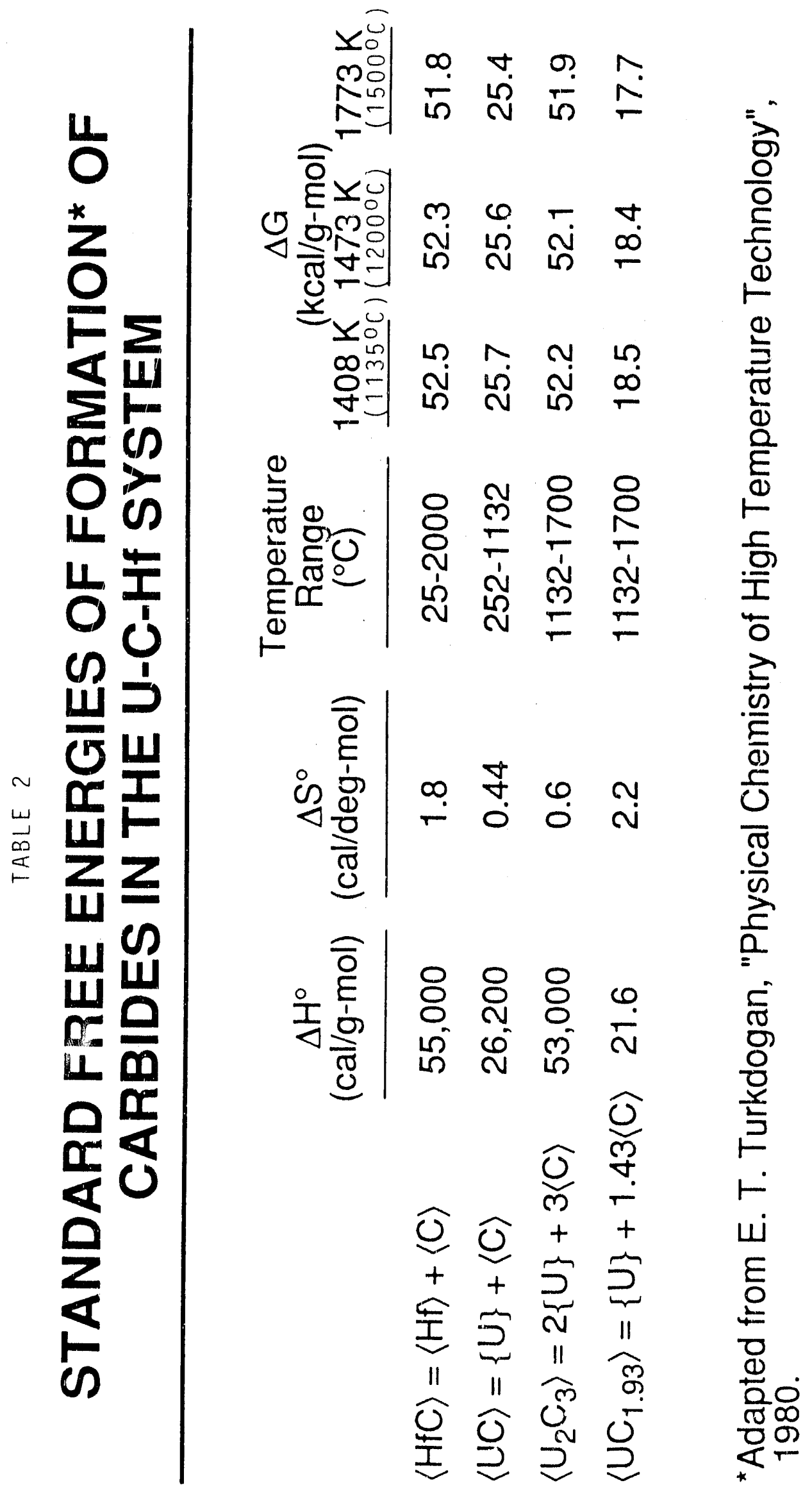


thermal-window within which the $\mathrm{HfC}$ is the most likely to form over other carbides.

\section{ANALYTIC MODEL SETUP}

The purpose of the analytic work is twofold: 1) To determine the analytic requirements for accurately simulating the temperature profile of the solidification process, particularly at locations where $\mathrm{C}$ reductions are noted, and 2) to provide thermal profile predictions for scaling-up to larger castings. This report addresses only the first aspect of the intended objective. The second aspect will be discussed in a subsequent report.

Schematics of the experimental vacuum-induction melting (VIM) system and the analytic model setup used to simulate the solidification process are shown in Figs. 1 and 2, respectively. Symmetry planes $(x=0$ and $z=0$ ) make it necessary to model only one-quarter of the book mold end caps, and firebrick (Fig. 2a). Although the cross-sectional shape of the end caps is circular, a rectangular geometry was used to simplify the 3D model. The initial temperature distribution for the simulations was based on the thermocouple readings prior to the pouring of the liquid $U$ into the book mold. The pouring of the liquid $U$ was assumed to occur instantaneously and a gray, diffuse radiation model was used. Radiation exchange factors, defined as fractions of heat energy leaving one surface that is absorbed by another, were assumed at appropriate boundaries. Initially a $1 \mathrm{D}$ model was used to predict the predominant direction of heat loss; but a 3D model was necessary to more accurately simulate the temperature profiles and the time to complete the solidification in the upper portion of the book mold. Material thermal properties were initially assumed to be independent of temperature; and the material properties of unalloyed $U$ have been assumed for the U-Hf alloy. However, subsequently, temperature dependent properties were incorporated into the model to improve its predictive accuracy. The response time of the book mold temperature is much more realistic utilizing these temperature dependent material properties. Therefore, the predictive accuracy of the model is significantly improved. Figs. 3-a and -b illustrate the temperature dependence of both graphite and uranium properties. Due to the unavailability of ternperature dependent data for the density of graphite $\left(\rho_{\mathrm{g}}\right), \rho_{\mathrm{g}}$ was assumed to be constant. Some of the other temperature dependent properties used were those available from the Lawrence Livermore National Laboratory Materials Library utilized by HEATING6.1 ${ }^{4}$.

\section{RESULTS AND DISCUSSION}

Metallographic observations indicate that the carbides that form are concentrated in the top $13 \mathrm{~mm}$ to $25 \mathrm{~mm}$ of the book mold castings. A much smaller volume fraction is present in the bottom $25 \mathrm{~mm}$. However, between $25 \mathrm{~mm}$ and $165 \mathrm{~mm}$ (Fig. 4) the volume fraction of apparent carbides is significantly reduced (Fig. 5). Chemical analyses indicate that there is a significant reduction in carbon and hafnium contents in these regions where there are less carbides apparent (Table 3). Hence, the regions in the castings that exhibit less carbide precipitation correspond to areas that are significantly more carbides present. These results indicate that either 1) Hf does preferentially react with $\mathrm{C}$ and that these $\mathrm{Hf}$ carbides predominantly "floatup" to the top of the castings or 2) $\mathrm{C}$ and $\mathrm{Hf}$ are both expelled at the 


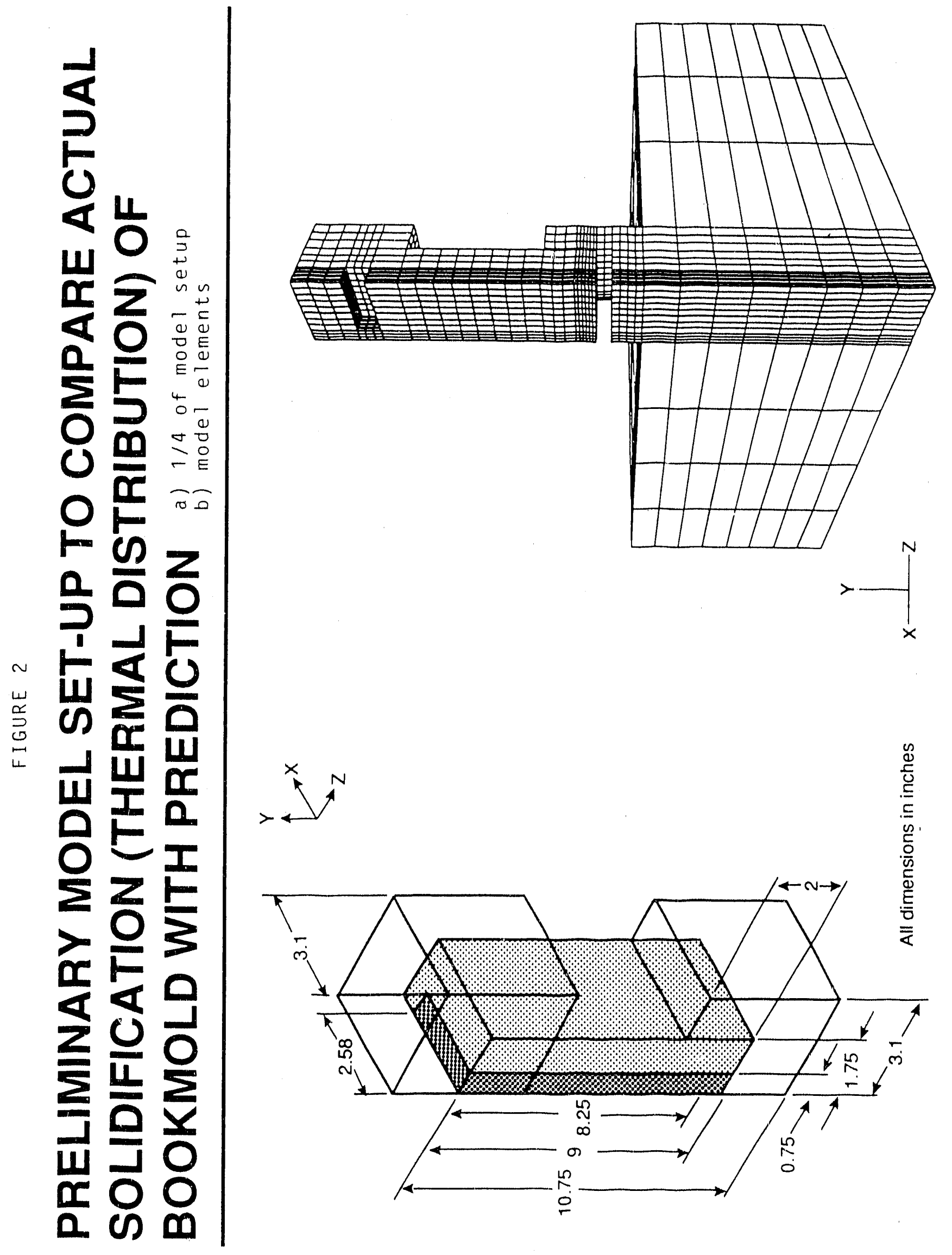

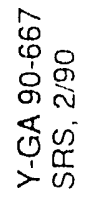




\section{FIGURE 3}

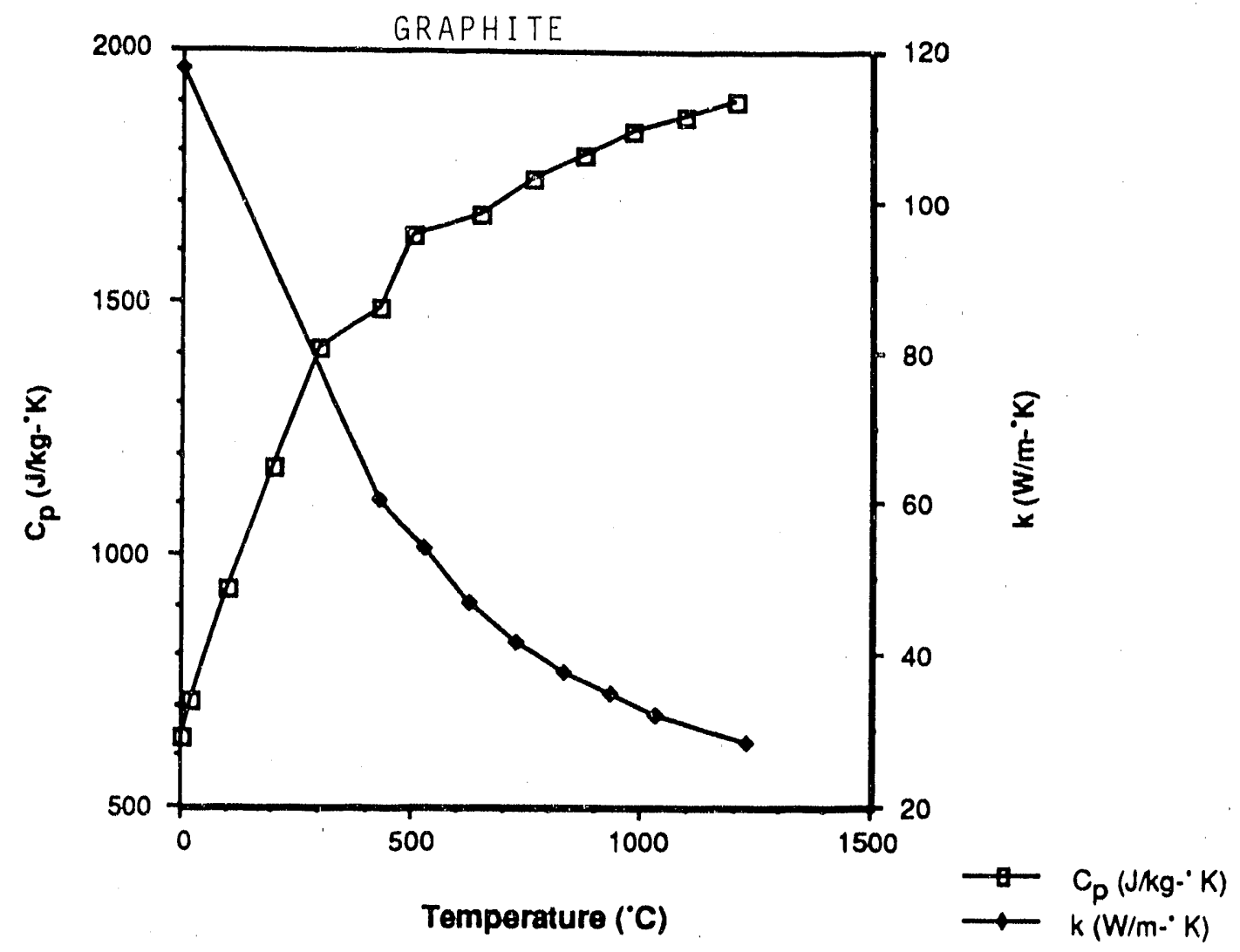

(a)

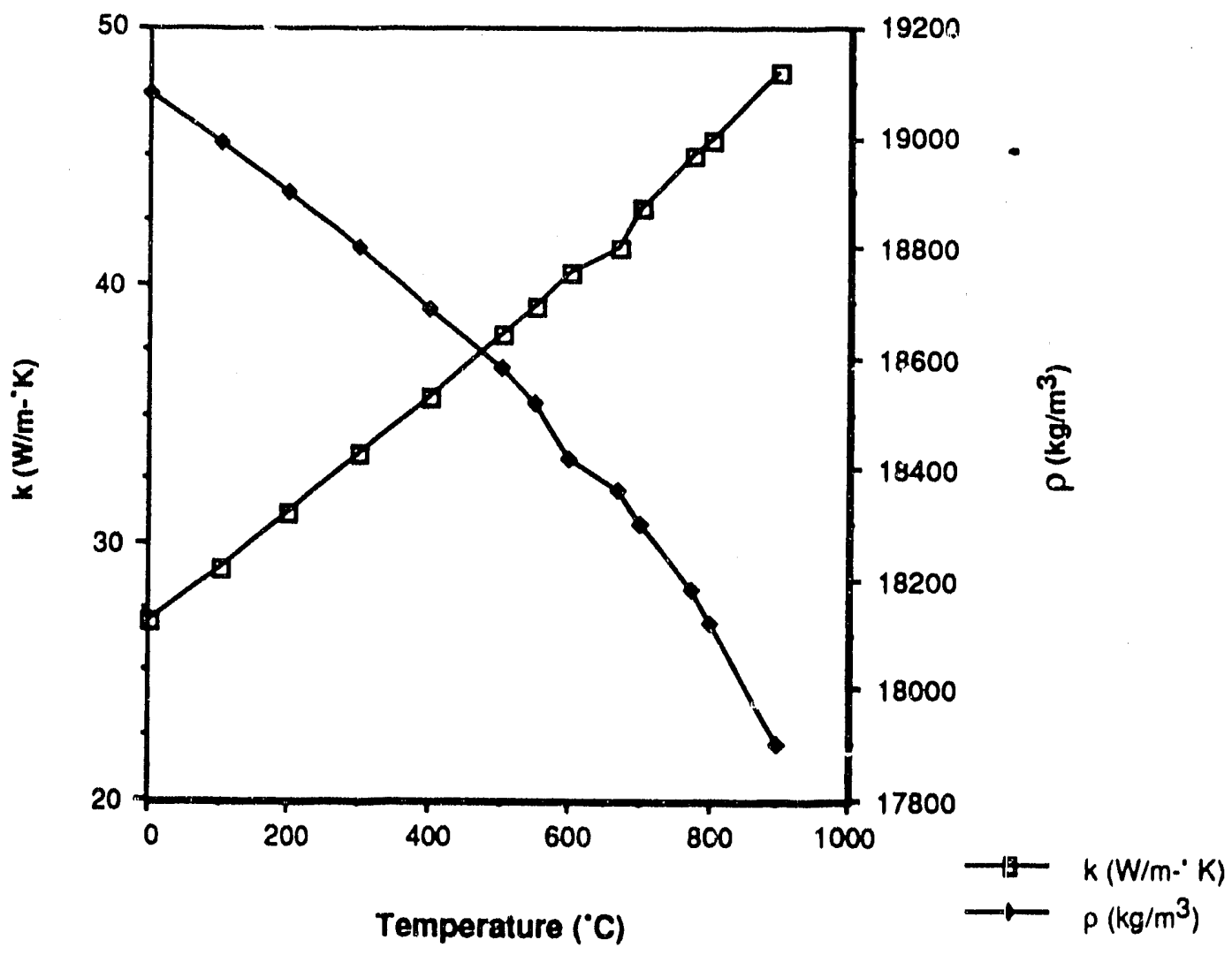

(b) URANIUM 


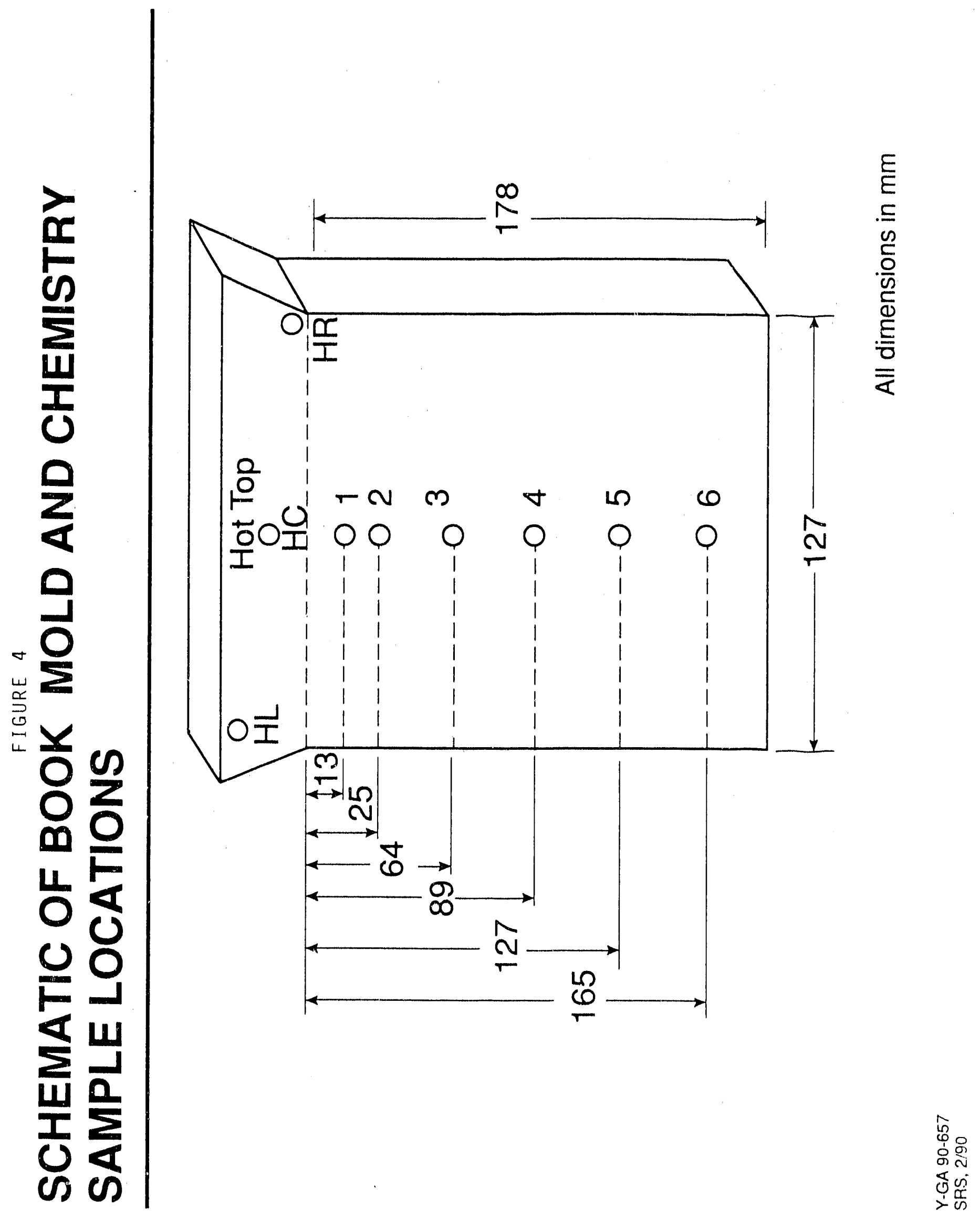



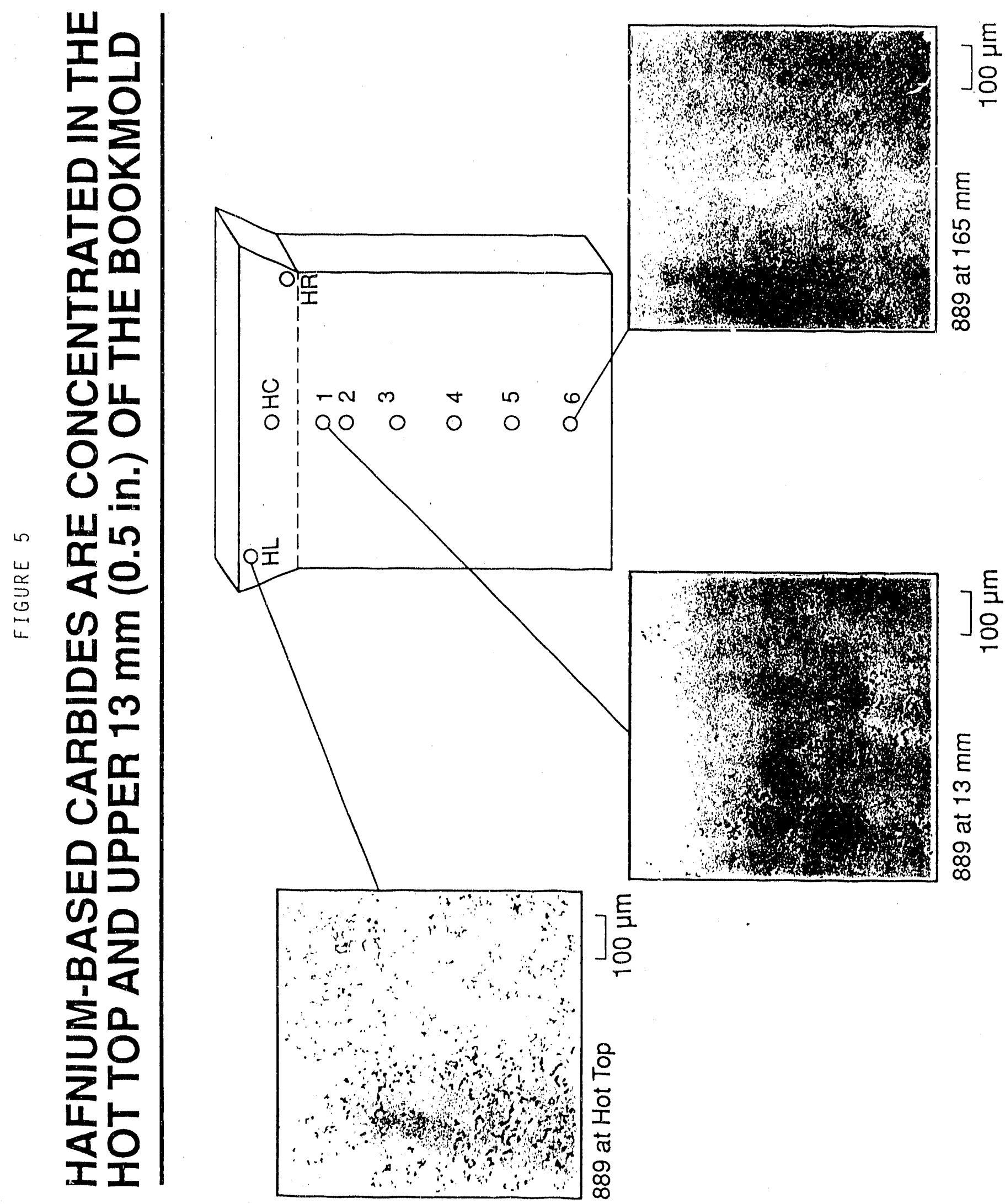

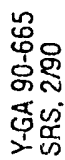





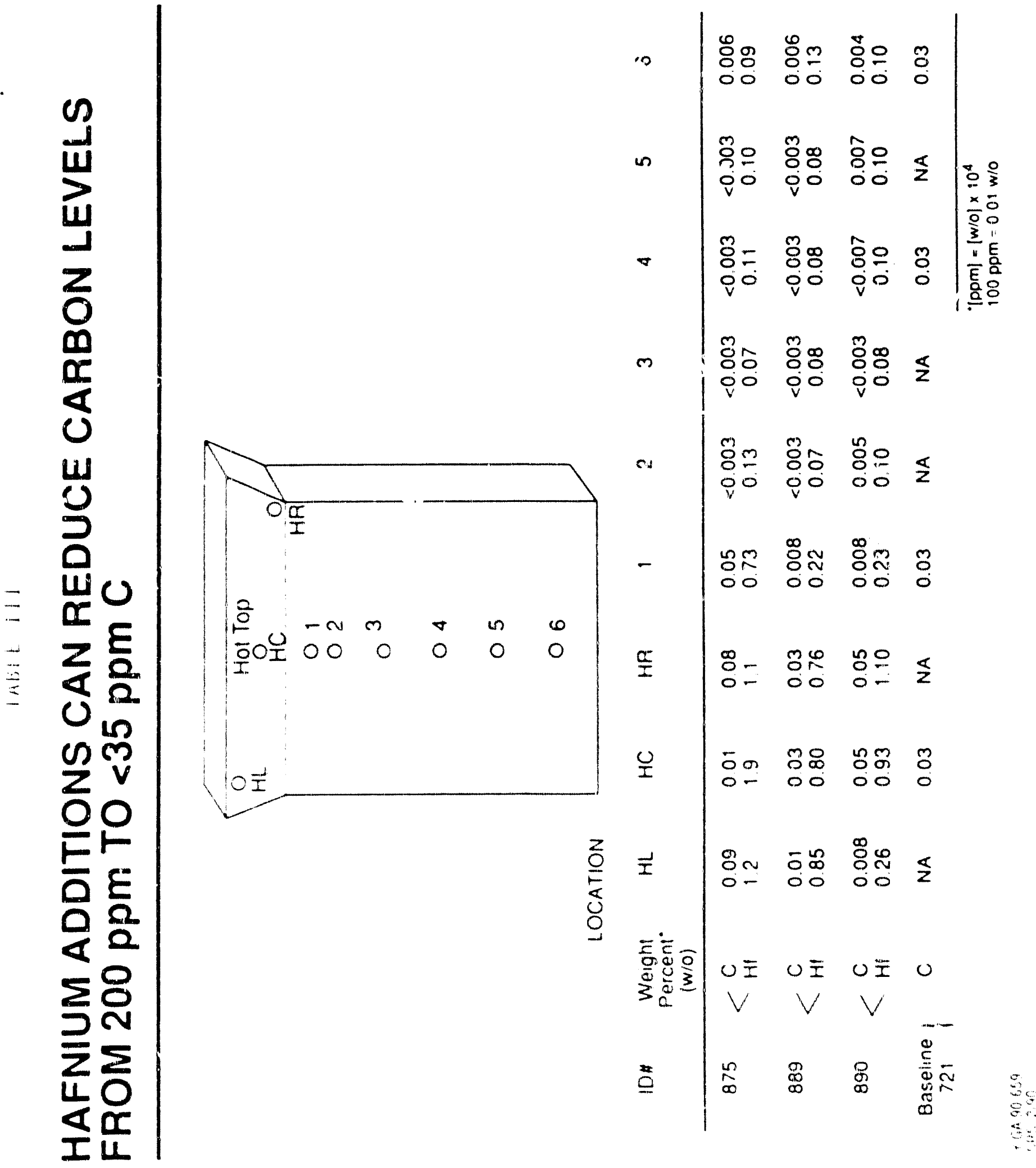


solidification front as it progresses up the ingot, and accumulate in the last liquid to solidify in the hot top, as in zone refining processes; or 3) A combination of both mechanisms is operational. The bottom end of the book mold assembly (which is usually intentionally located outside the induction coils so that uniaxial (directional) cooling is achieved) does not attain the same degree of thermal heating or cooling as the rest of the assembly. Therefore, the bottom of the book mold casting may not be in the "critical" temperature range for sufficient time so that the HfC can form and subsequently "floatout".

\section{ANALYTIC RESULTS AND DISCUSSION}

Some resistance to heat flow exists at the nonperfect thermal contacts present at other interfaces between a) the book mold and end caps, and b) the bottom end cap and firebrick. In most instances the gaps are filled with air. Therefore, the heat transfer across these gaps ran occur by both conduction and radiation. Different size gap regions were modeled betwean the bottom end cap and the tirebrick insulation. All of the outside surfaces of the model vere assumed to be insulated. Fig. 6 illustrates how the 3D model results vary as a function of different gap assumptions. Fig. 6a demonstrates the differences between the experimental data and the thermal profile generated by the model for the perfect thermal contact case. Overall, the model underpredicts the temperatures recorded by the top and middle thermocouples. However, during the initial 25 seconds the model does seem to agree fairly well with the experimental data. When blackbody radiation is assumed within the gap (Fig. 6b), the model still underpredicts the temperatures for the top $\mathrm{TC}$, but initially overpedicts the middle $\mathrm{TC}$. However, the model temperatures fall precipitously after approximately 50 seconds and underpredict the experimentally observed values. To study the effect of varying the amount of radiation through the gap, the exchange factor was reduced to 0.05 . The thermal prediction for $\mathrm{TC}_{\text {Top }}$ remained the same as previously calculated, but the predictions for $\mathrm{TC}_{\mathrm{MDL}}$ were initially , higher than observed, and then fell short of the actual data after approximately 75 seconds. Hence, as expected, the gap regions appear to provide resistance to heat transfer between the bottom end cap and the firebrick.

Being able to successfully reduce the tate of heat loss in the model utilizing one gap prompted the implementation of a second gap in the model. The second gap was located between the side of the book mold and the end cap. Initially, the exchange factor was assumed to be equal to 1.0 with blackbody gap radiation. Figs. $7 \mathrm{a}$ and $\cdot \mathrm{b}$ compare the simulation results for this case. For the first 70 to 75 seconds. the model predictions match the actual heat-up rates of $\mathrm{TC}_{\mathrm{Top}}$ and $\mathrm{TC}_{\mathrm{wD}}$. However, tor times greater than 75 seconds the model predicts a lower maximum temperature for both thermocouples, and the analytically determined temperature peaks occur approximately 100 seconds sooner the, 1 the experimentally measured peaks. Both of these results indicate that the heat loss is still too rapid in the model. Hence, since the boundary heat transfer coefficient (BHTC) at the bottom of the mold assembly is not accuratcly predicting the actual thermal profiles generated during the casting process, the BHTC needs to be simulated more accurately. In order to determine an upper limit on the amount of heat retained in the took mold throughout the solidification process, the radiation subsequently was assumed to be zero in both of the gaps (Fig. 7c). This latter specification only dramatically increased the predicted rate heatup of $\mathrm{TC}_{\mathrm{MDC}}$; the model prediction for the heatup of $\mathrm{TC}_{\mathrm{Top}}$ remained essentially unchanged over the 50 seconds the model was run. The continued discrepancy between the actual temperature measured at $\mathrm{TC}_{\mathrm{BTM}}$ and the temperature predicted 
FIGURE 6

A COMPARISON OF EXPERIMENT VERSUS ANALYTIC (HEATING) THERMAL PROFILES AS A FUNCTION OF GAP ASSUMPTIONS.

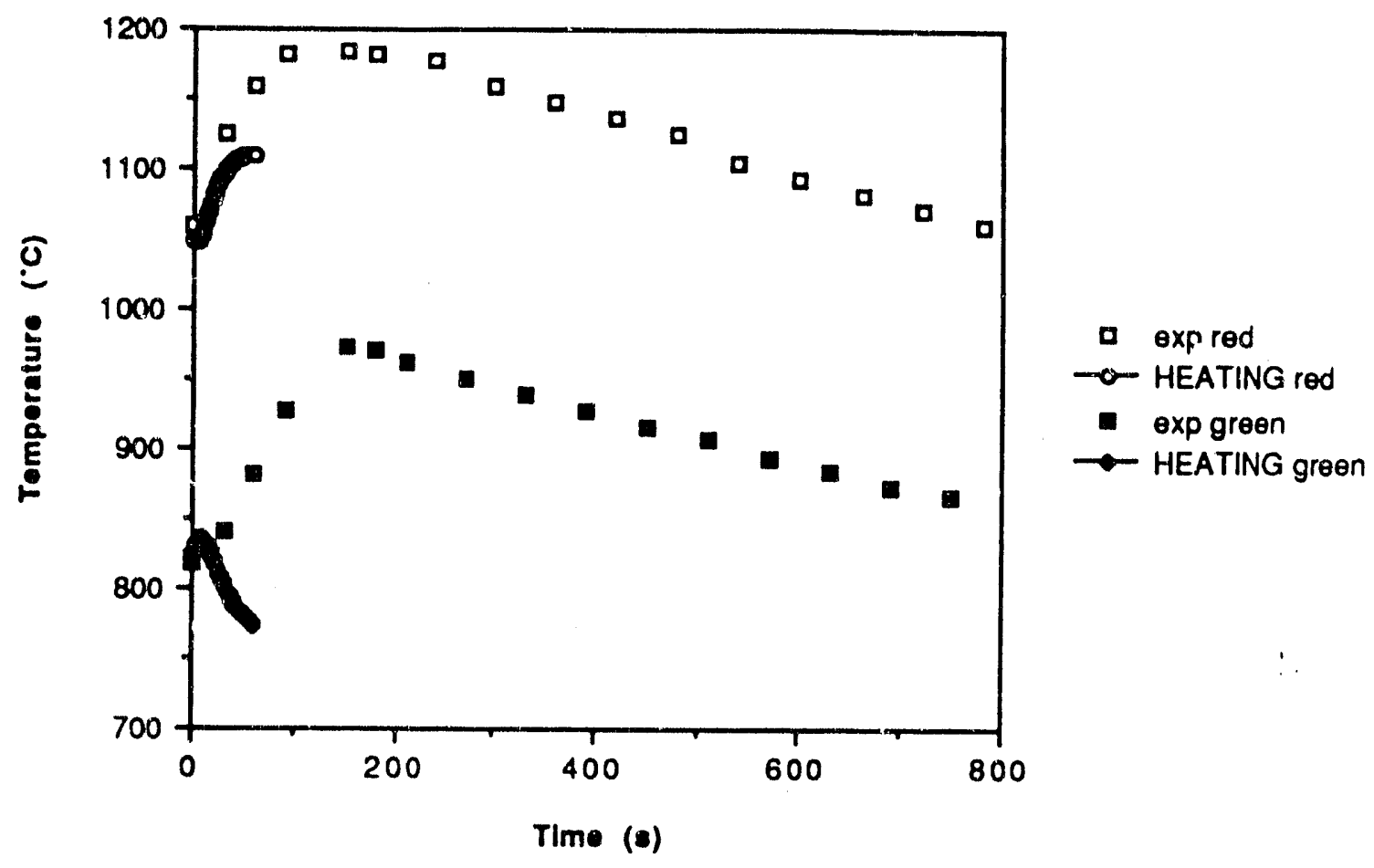

(a) Perfect Thermal Contact

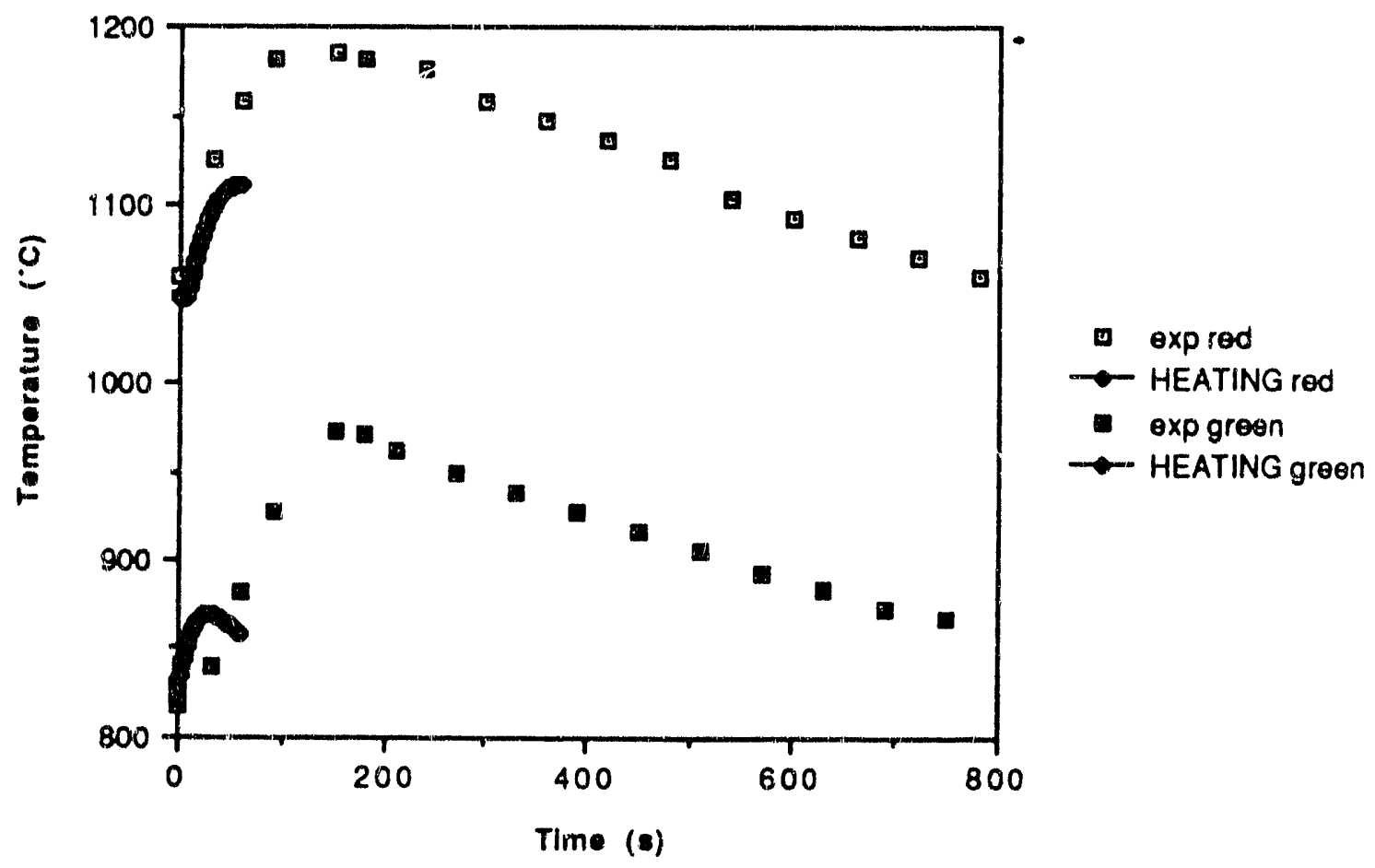

(b) 1.0 inch gap 
FIGURE 6

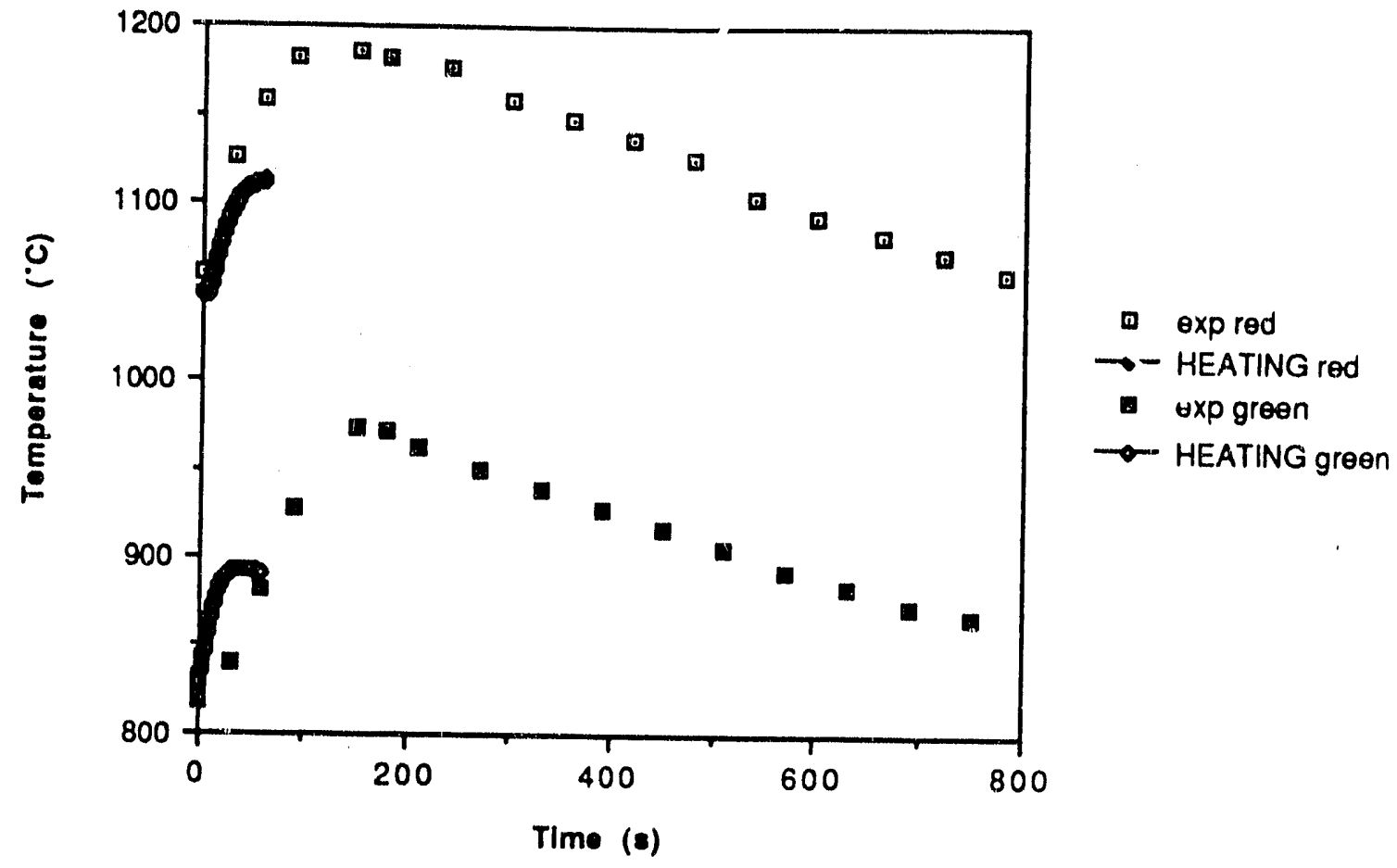

(c) 0.05 inch gap 

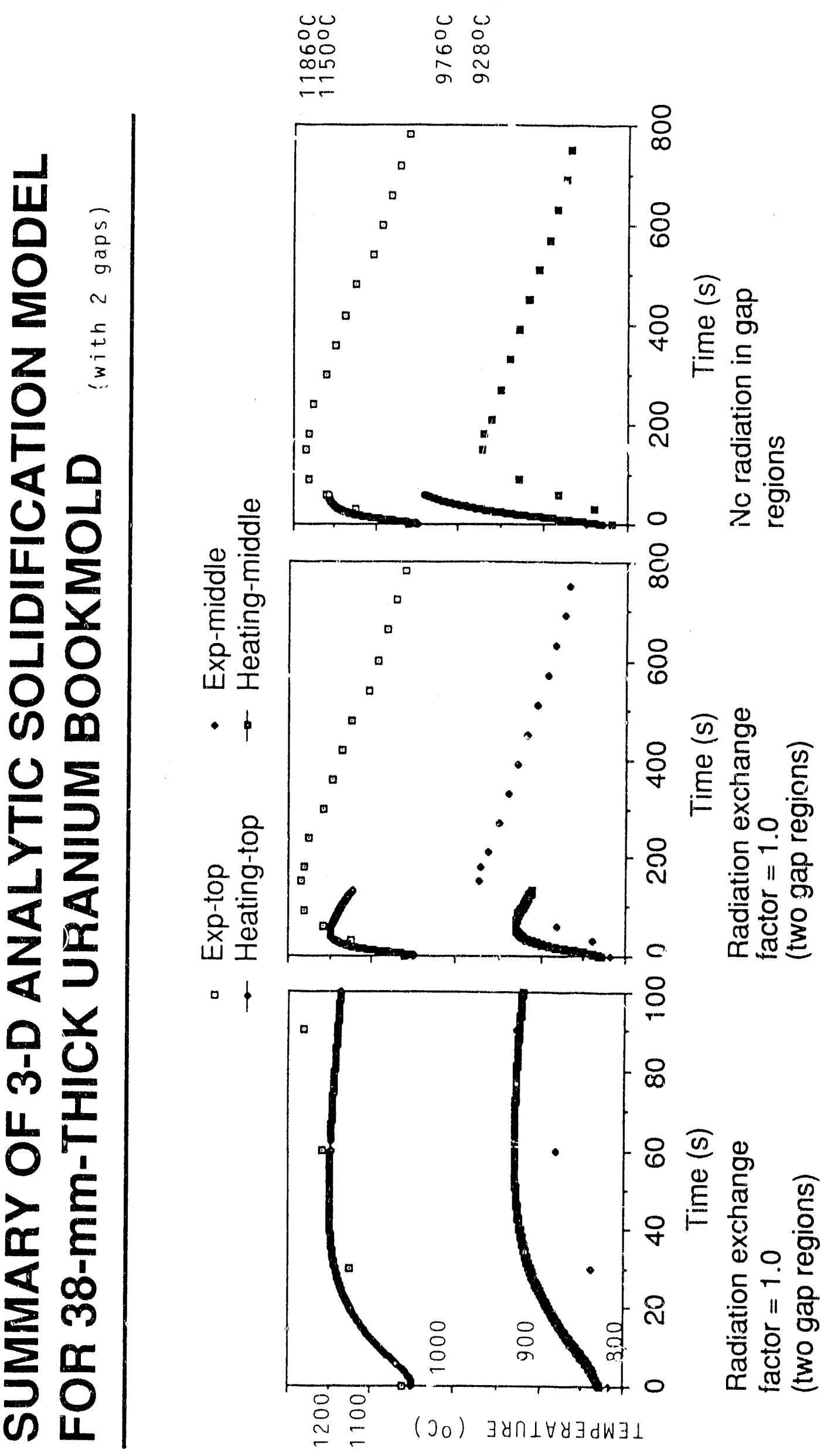
by the model seems to indicate that the temperature at $\mathrm{TC}_{\mathrm{BTM}}$ immediately before pouring may be lower than the model assumes. This discrepancy is currently being scrutinized.

Isotherms within the book mold were also studied as a function of time after pouring the liquid $U$ into the mold. The temperature gradient was essentially uniaxial; and as anticipated, the lower portion of the casting solidifies firs. This type of temperature profile will accommodate both the HfC floatation and the solidification-front carbide formation expelling mechanisms.

\section{CONCLUSIONS}

The addition of $\mathrm{Hf}$ has been found to reduce $\mathrm{C}$ levels in depleted $\mathrm{U}$ during the casting process. A preliminary analytic model of the solidification process has been set up and is being evaluated. Although the gap regions provided noticeable resistance to heat transfers between the lower end cap and the firebrick, there still is a large discrepancy between the simulated and observed temperature data. Therefore, the boundary heat transfer coefficient at the bottom of the mola assembly and the initial sat-up conditions assumed for the model may need to be simulated more accurately. The temperature gradient in the castings facilitates HIC concentration in the hot top.

\section{FUTURE WORK}

Mechanical tests are being planned to determine the effects of any residual Hf or HFC on strength and ductility. In addition, furthe: model enhancements are being considered so that ihe predicted thermal profiles will more accurately predict the actual, experimental temperatures. Once this is accomplished, it will be possible to begin simulating the starting thermal conditions required for eliminating $C$ in much larger castings. The latter accomplishment will enable $C$ levels to be reduced in recycled $U$ to near-virgin derby levels.

\section{REFERENCES}

1. J. B. Condon and C. E. Holcombe, Ir., "Kinetics of the Yttria-Carbon Reaction," High Technology Science 18, 79-85 (1984).

2. R. H. Reiner and C. E. Holcombe, Jr., "Carbon Monoxide Interactions with Liquid Uranium," Y-DU-485, Martin Marietta Energy Systems, Inc., Oak Ridge Y-12 Plant, April (1986).

3. R. H. Reiner and C. E. Holcombe, Jr., "Carbon Monoxide Reaction with Liquid UraniumNiobium Alloys," Y-2378, Martin Marietta Energy Systems, Inc., Oak Ridge Y-12 Plant, December (1986).

4. K. W. Childs, G. E. Giles, C. B. Bryan, and C. K. Cobb, HEATING: A Computer Program for Multi-dimensional Heat Transfer Analysis (ver. 6.1) ORNL/NUREG/CSD-2/VS/R3, Martin Marietta Energy Systems, Inc., Oak Ridge Gaseous Diffusion Plant, January (1988). 

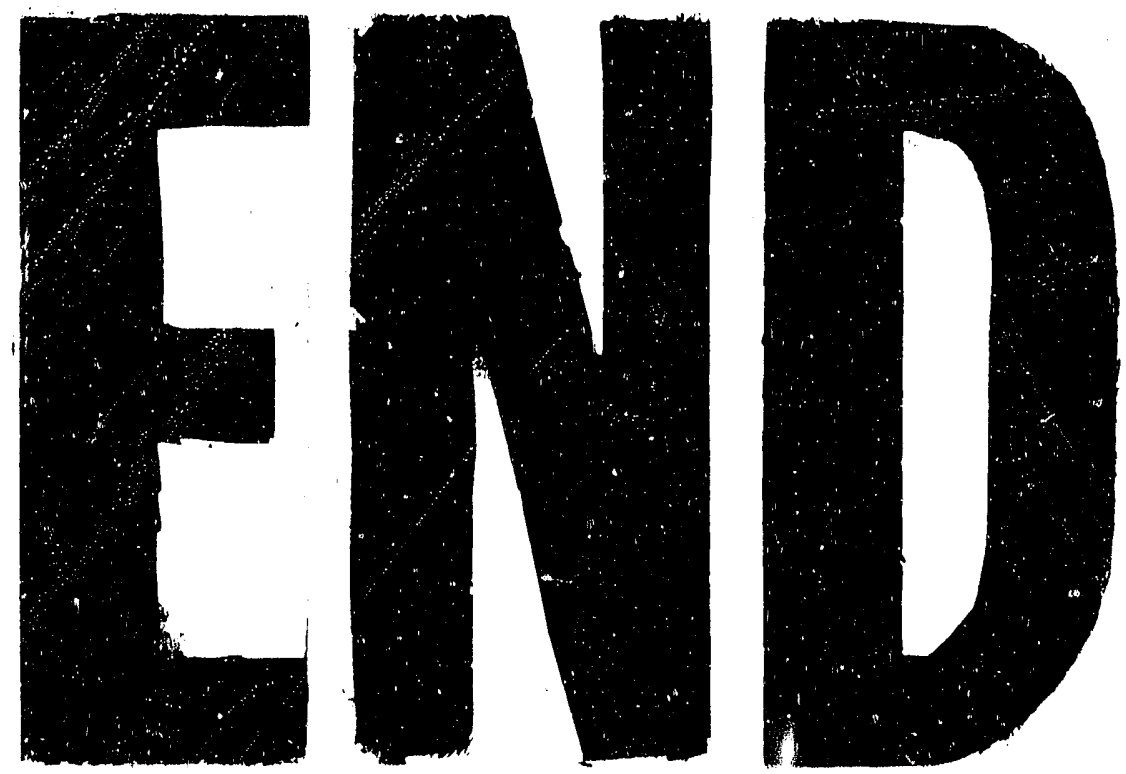

1
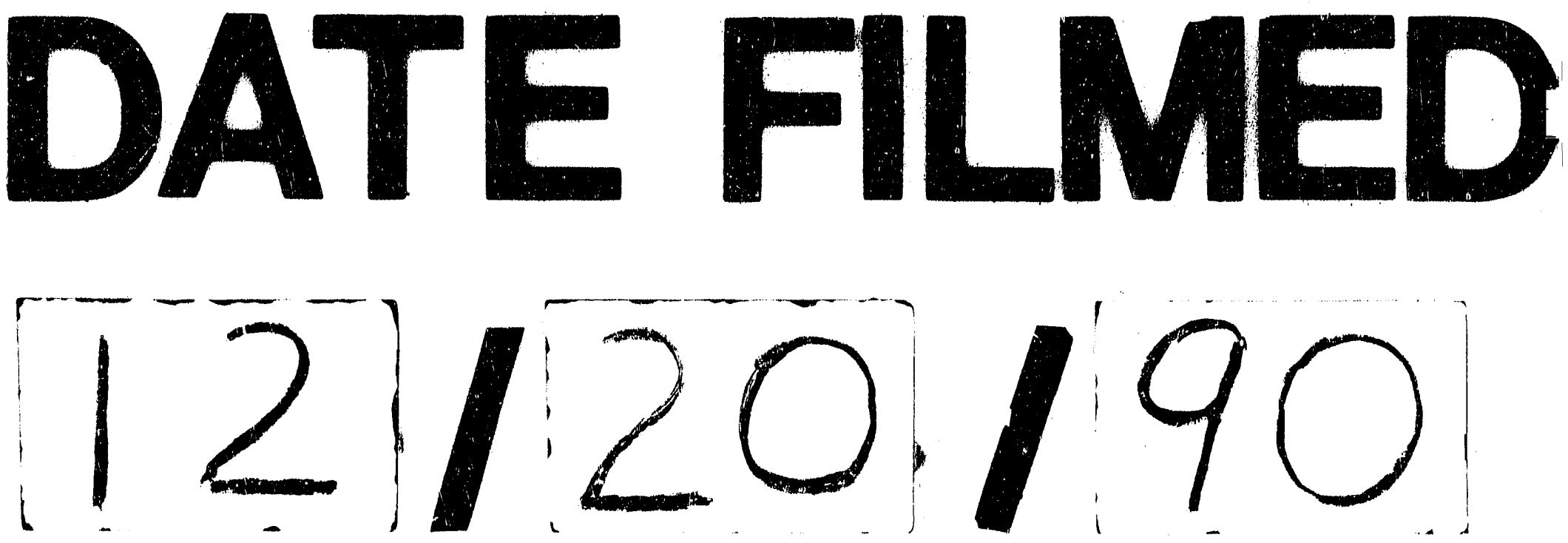
